\title{
Equatorial electrojet as a diagnostic tool of geomagnetic field models
}

\author{
Heather McCreadie and Toshihiko Iyemori \\ World Data Center for Geomagnetism and Space Magnetism, Graduate School of Science, Kyoto University, Kyoto 606-8502, Japan
}

(Received July 11, 2005; Revised December 19, 2005; Accepted December 19, 2005; Online published July 26, 2006)

\begin{abstract}
The equatorial electrojet (EEJ) is a unique feature of the Earth's external current systems because it must flow along the dip equator. This provides us with a tool to determine the nature of the variations imposed by competing main field models on the equatorial region. First we show that for certain regions a comparison between scalar geomagnetic measurements that use different models to remove the main field may not be reasonable. Next we found the intrinsic error in the determination of the possible location of the dip equator was $\pm 9.8 \mathrm{~km}\left(0.088^{\circ}\right)$ at $108 \mathrm{~km}$ altitude for the models shown here. Using scalar measurements from over 14,000 CHAMP satellite passes, the latitude of the maximum of the EEJ field at the satellite altitude was determined by subtracting four different models of the main field. We find that the location can be statistically determined to within $\pm 0.5^{\circ}$ of the dip equator (calculated at $108 \mathrm{~km}$ altitude) irrespective of longitude, time of the measurement, degree of magnetic activity, and subtracted model. However, variations of the latitude of the maximum EEJ field with longitude are sometimes caused by the actual model and are not always a physical phenomenon. By choosing one model, and assuming it is the best representation of the main field, we have also shown that the accuracy of determination of the position of the EEJ signal is reduced in the morning and evening hours and that a morning and evening shift in the location of the EEJ found using ground measurements is also seen here. There exists a clear annual variation in the position of the EEJ regardless of longitude: it is south of the dip equator in December which is in agreement with the findings of all previous studies.
\end{abstract}

Key words: Equatorial electrojet, geomagnetic field, lithospheric field, main field modelling, core field, CHAMP, Oersted.

\section{Introduction}

The reason for embarking upon this study was we noticed several colleagues comparing magnetic data obtained from satellite measurements by using different models to remove the main field. Competing magnetic main field models adduce no reasons for choosing between them. Therefore this paper is aimed at users of such models rather than the modellers.

The Earth's main magnetic field can be described using Gauss coefficients derived from a spherical harmonic analysis (Chapman and Bartels, 1940). For convenience, in this paper we will separate each model main field into a core field (harmonics of degrees 1-15, with its secular variation), and a lithospheric field (degrees above 15). This definition is based loosely on the power spectrum of the main field model derived from Magsat data in Langel and Estes (1982) where the rate of change of the power spectrum changes abruptly somewhere between degrees 14 and 16. Since the lithospheric model, MF3 (see Table 1) begins at degree 16, degree 15 was chosen as the truncation point describing the core field. Examples of each are given in Fig. 1.

As discussed by Chambodut et al. (2002) the main field models differ because of different spherical harmonic parameterisations and differing data selection. The data are selected from satellite passes flown on the night side of

Copyright (c) The Society of Geomagnetism and Earth, Planetary and Space Sciences (SGEPSS); The Seismological Society of Japan; The Volcanological Society of Japan; The Geodetic Society of Japan; The Japanese Society for Planetary Sciences; TERRAPUB the Earth during magnetically quiet periods. This is necessary as each measurement is the summation of all magnetic fields from all sources. Using night time reduces the number of sources by removing the day-time ionospheric sources and using magnetically quiet times reduces the effect of disturbance fields. Days deemed magnetically quiet by modellers differ because of the different definitions of magnetically quiet days. The definition of "night" is also dissimilar between the models. Also, some models incorporate satellite vector and scalar field measurements, and ground measurements. The four chosen for this study use only satellite measurements. Table 1 describes the field models we use.

This paper contains a comparison of the field models used, a discussion on the dip equator and how it varies with height, longitude, time and model. This is followed by a description of the CHAMP data and the reduction method implemented. The next section describes the differences in the position of the EEJ between the chosen models. Then using one model we show that outliers are not caused by magnetic activity and we conclude with details regarding local time and universal time, variation in the position of the EEJ.

\section{Comparison between the Field Models}

It is interesting to see how the models compare graphically. In the literature there are many comparisons of the coefficients (for example Maus et al., 2002) but to get a feel for what it means a graph is sometimes better. 

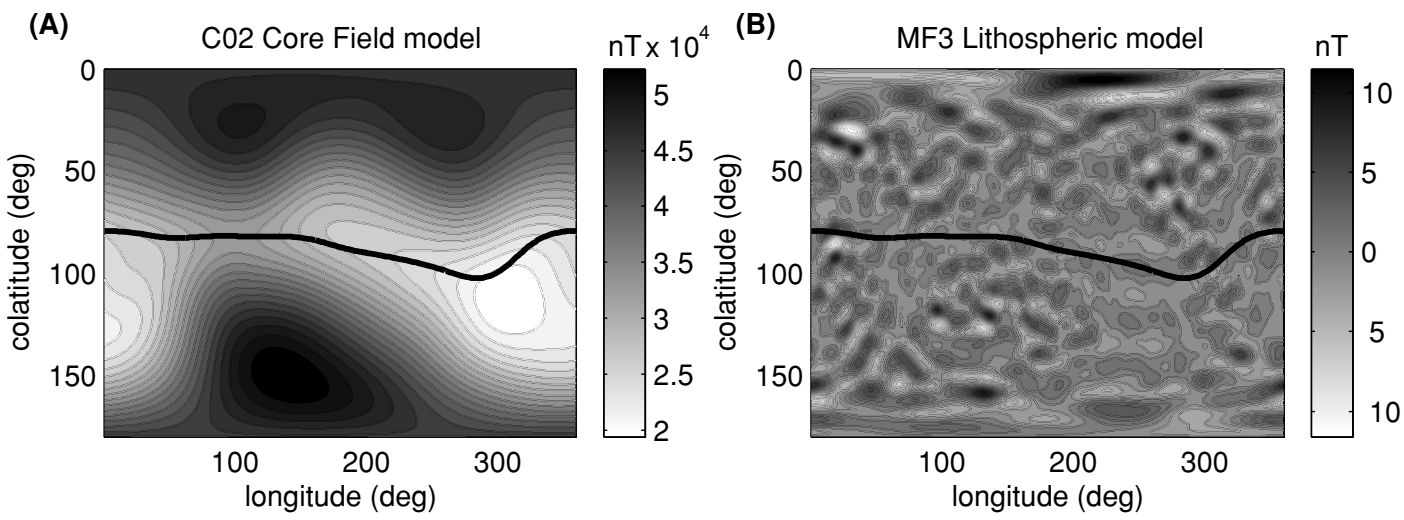

Fig. 1. (A) Intensity of the $\mathrm{C} 02$ core field model (gauss coefficients 1-15) at $430 \mathrm{~km}$ altitude. (B) Intensity of the MF3 lithospheric model (gauss coefficients $>15$ ) at $430 \mathrm{~km}$ altitude.

Table 1. Description of Field models. For information on the terms in column 2 see the references given in column 1. See http://www.dsri.dk/Oersted/ Field_models/ for the model coefficients.

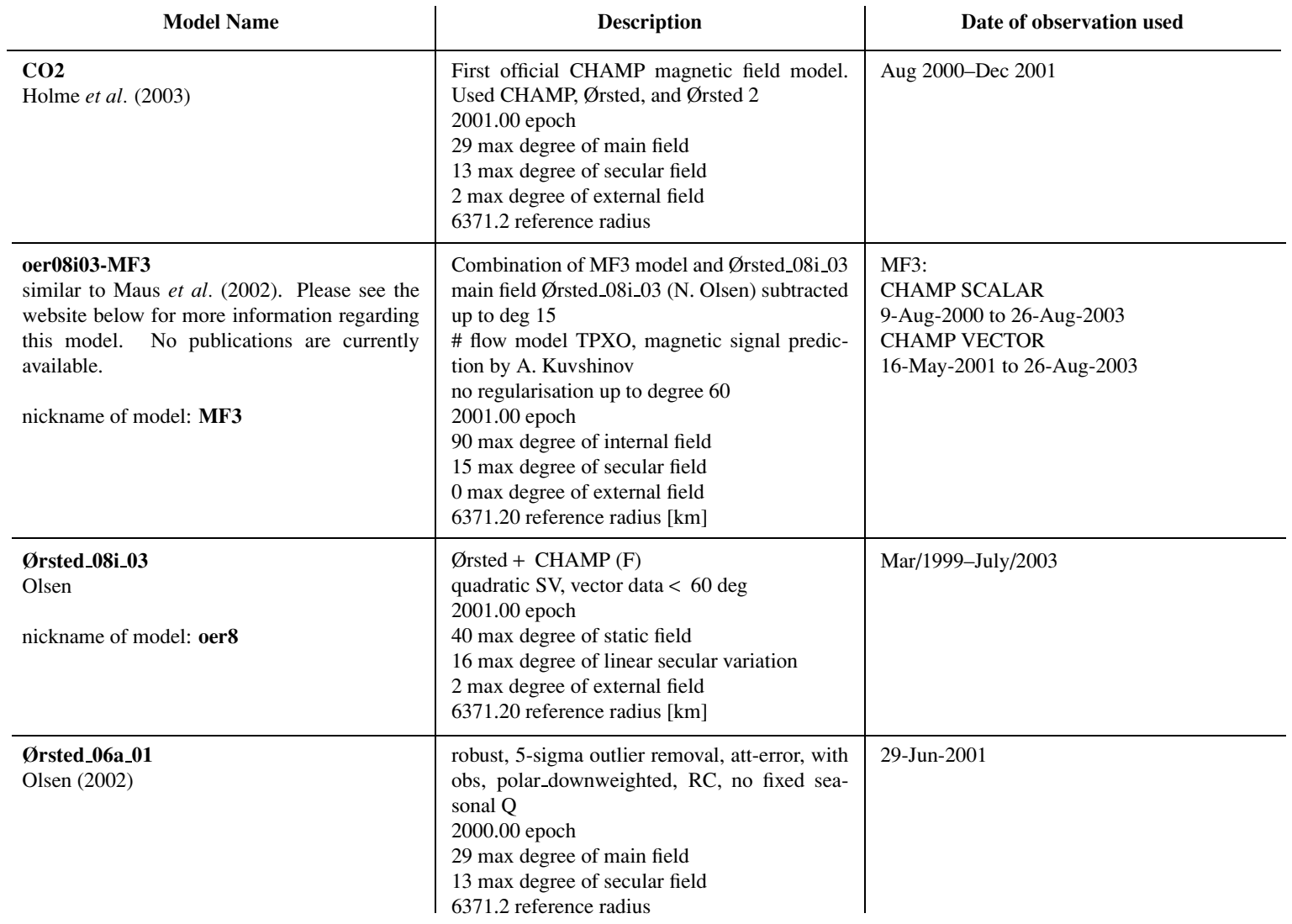

Figure 2(A) shows the difference between the C02 model and the Ørsted_08i_03 model for the core fields. The models were calculated for altitude $430 \mathrm{~km}$ and day 900 from 2000.00. It can be seen that in the equatorial and midlatitude regions there are long wavelength features having a magnitude about 5 nT. Discordant long wavelength features will be apparent between the reduced satellite data sets because of long wavelength disparities between the two models which have been subtracted.

Figure 2(B) shows the difference between the lithospheric fields of the two models. There are again differences of amplitude $5 \mathrm{nT}$, but now of much shorter wavelength. This has shown that for certain regions a compar- ison between data that use different models to remove the main field may not be reasonable.

To compare only lithospheric models, Fig. 2(C) shows the difference between the Ørsted_08i_03 and the MF3 models. They both use the same core field model so the difference here shows the disparity between the lithospheric models only. The ordinate range is from 40-140 colatitude to highlight the mid-low latitudes. The differences are of the order $3 \mathrm{nT}$ : considerably less than between the $\mathrm{C} 02$ and Ørsted_08i_03 model (for the mid latitude range an order of $6 \mathrm{nT}$ for the disparity is shown) suggesting that the core field determination is very important for determining the lithospheric field. 
We will see later that these lithospheric disparities are of the same sort of wavelength as that of the magnetic signature of the EEJ. The magnetometer does not distinguish between the two contributions, so at any one longitude the latitude of the maximum observed "EEJ" field could well be changed. So any variation of latitudinal position with longitude could be different when different field models are subtracted. If a comparison between parameters of the EEJ were considered when competing lithospheric models were used to remove the data then false conclusions may be drawn for certain longitudes. A parameter that is easily determinable using scalar field magnetic data is the location of the field minimum near the magnetic equator. However, to determine this all magnetospheric and internal field signatures must be first removed from the signal and an invariant zero line should be drawn to determine the EEJ location.

\section{Comparison between the Dip Equators}

Using ground measurements Fambitakoye and Mayaud (1976/2) were able to show that the position of the afternoon and morning EEJ were $40 \mathrm{~km}$ more northward than those at midday: $40 \mathrm{~km}$ is approximately $0.34^{\circ}$ latitude at the Earth's surface. Therefore a resolution of $0.1^{\circ}$ for determining the position of the EEJ is sought in the satellite data. Here the dip equator is calculated as the zero point of the $\mathrm{Z}$ component of the main field model of angular degrees 1-14 (including secular terms). The altitudes are determined from the reference sphere used by the models of radius $6371.2 \mathrm{~km}$ (the mean radius of the Earth). The dip equators for the Ørsted_08i_03 and the MF3 models are the same because they use the same main field model. However, Fig. 3 is a contour plot showing the variation with longitude and altitude of the difference between the location of the dip equators given by the $\mathrm{C} 02$ models and the Ørsted_08i_03 models for day 1398 after 2000.00. At the approximate altitude of the Ørsted satellite $(800 \mathrm{~km})$, is between $\pm 0.01^{\circ}$.

The difference increases as altitude decreases, being in the range $\pm 0.01^{\circ}$ at $800 \mathrm{~km}$ (approximate altitude of Ørsted), $\pm 0.015^{\circ}$ at $400 \mathrm{~km}(\mathrm{CHAMP}), \pm 0.025^{\circ}$ at $108 \mathrm{~km}$ (EEJ), and $\pm 0.027^{\circ}$ at the surface. It is clear from comparing the model dip equators that when two models are used the maximum intrinsic error imposed upon the data set is $\pm 0.027^{\circ}( \pm 3.0 \mathrm{~km})$. This shows that both the $\mathrm{C} 02$ and the Ørsted_08i_03 main field models can be used to determine the dip equator to within the required resolution.

The latitude of the dip equator varies with altitude. Using the Ørsted_08i_03 model to show our point, the dip equator was calculated for various altitudes. Shown in Fig. 4 are the differences in latitude between the dip equator calculated at altitude $104 \mathrm{~km}$ (the minimum possible altitude of the peak current density of the EEJ, determined by rocket measurements from various sources presented in Onwumechilli, 1997, Chapter 2) for day 360.0 from 2000.0, and the dip equator calculated at various altitudes for the same time. The light grey and dark grey lines show the differences for altitudes $110 \mathrm{~km}$ and $120 \mathrm{~km}$ for the same day, respectively. The maximum absolute deviation from zero is $0.02^{\circ}(2.2$ $\mathrm{km}$ at altitude $110 \mathrm{~km})$ and $0.06^{\circ}(6.8 \mathrm{~km}$ at altitude 120 $\mathrm{km})$ near the 330 longitude zone for each altitude. If the
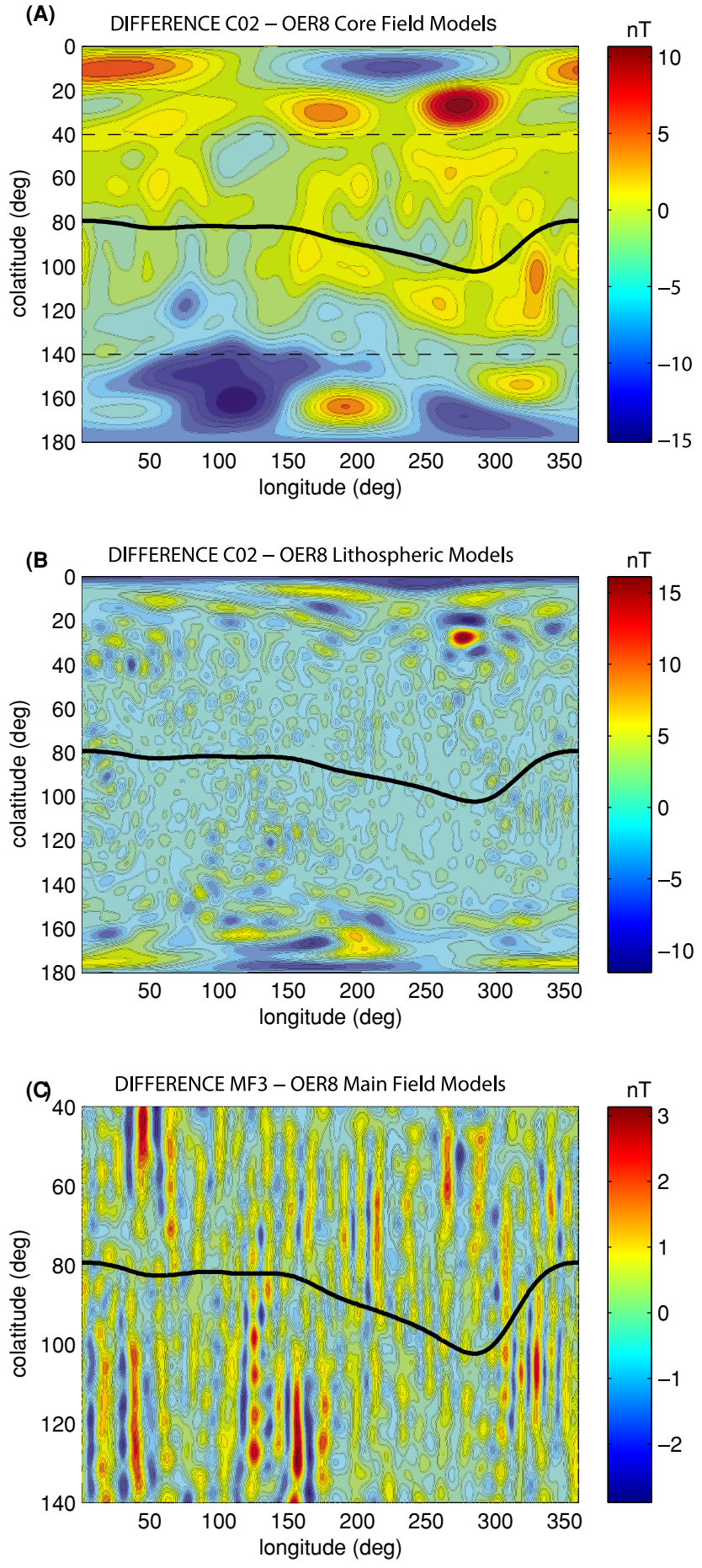

Fig. 2. (A) Differences between the intensities of C02 and Ørsted_08i_03 core field models at $430 \mathrm{~km}$ altitude. (B) Differences between the intensities of lithospheric parts of the C02 and the Ørsted_08i_03 models at $430 \mathrm{~km}$ altitude. (C) Differences between the intensities of Ørsted_08i_03 and MF3 lithospheric field models at $430 \mathrm{~km}$ altitude.

maximum current density of the EEJ was located at 120 $\mathrm{km}$ and $104 \mathrm{~km}$ was chosen as the invariant dip equator the maximum possible location error imposed by the choice of altitude is $\sim 0.06^{\circ}$. The black line shows the residuals for altitude $430 \mathrm{~km}$; the approximate altitude of the CHAMP satellite. There is an appreciable difference in the position of the dip equator between altitudes $300 \mathrm{~km}$ apart. Since the peak electrojet current usually forms close to $108 \mathrm{~km}$ alti- 


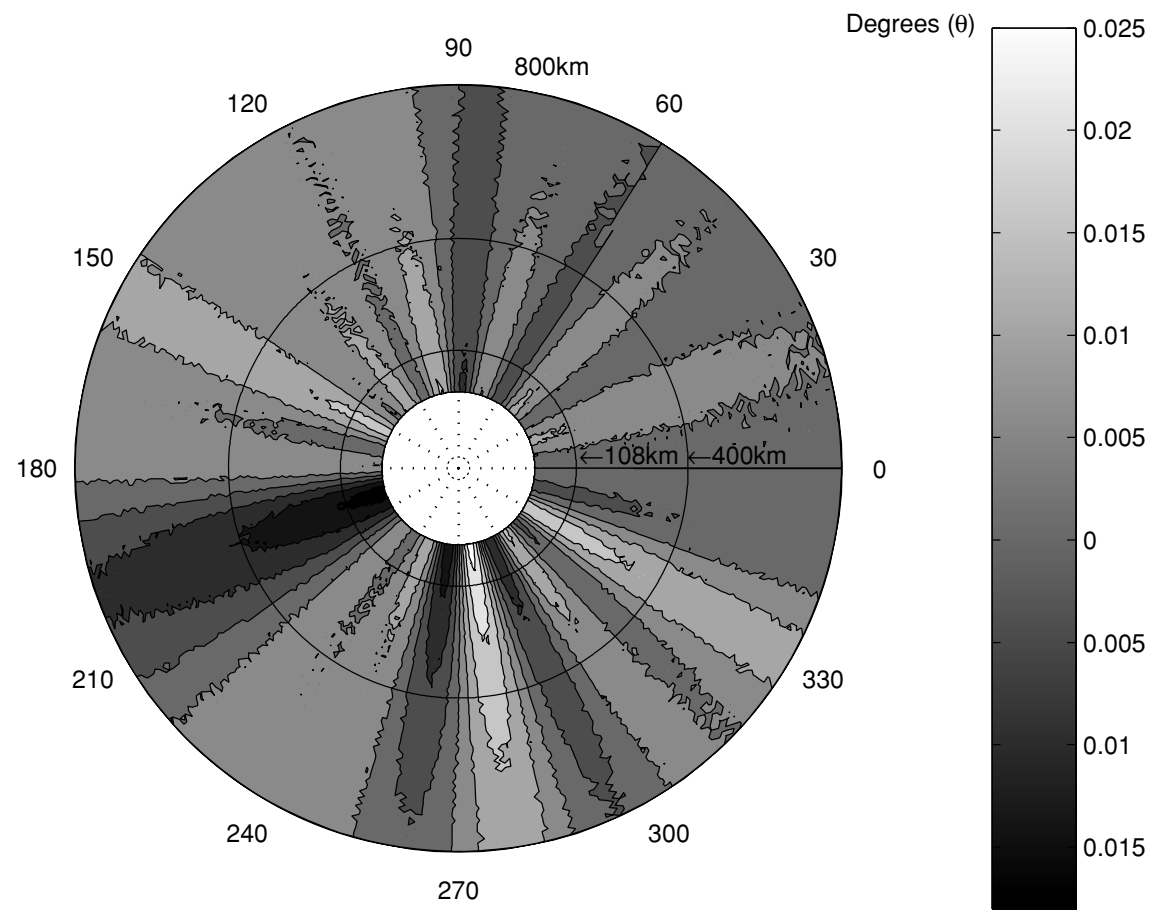

Fig. 3. Polar plot showing the differences between the position of the dip equator for the $\mathrm{C} 02$ models and the Ørsted_08i_03 models with altitude.

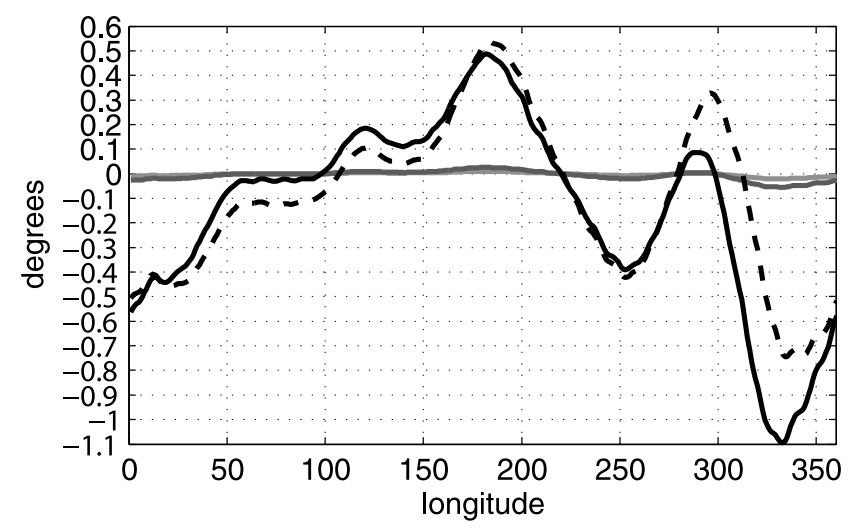

Fig. 4. The differences in latitude between the dip equator, calculated at altitude $104 \mathrm{~km}$; and the dip equator for $110 \mathrm{~km}$ (light grey line), and $120 \mathrm{~km}$ (dark grey line) and $430 \mathrm{~km}$ (black line) on the same day (360 days after 2000.0). The black dashed line shows the differences for altitude $430 \mathrm{~km}$ and day 1461 after 2000.0.

tude (see reviews) this altitude was chosen for the invariant altitude of the model dip equator.

The latitude of the dip equator is also varies with time. Using ground based measurements from the Indian Peninsular, Deka et al. (2005), and using satellite based measurements, Jadhav et al. (2002), showed that the geomagnetic secular variation influences the position of the dip equator by as much as 1 degree per decade. The main field models we use include secular variation terms (see Table 1). The black line in Fig. 4 is for altitude $430 \mathrm{~km}$ but day 1461: three years later than the calculation at the same altitude. The graph shows appreciable changes in the modelled dip latitude, up to 0.5 degrees in places. Hence, secular variation must be taken into account when dealing with 4 years of measurements. We have done this, but any error in the secular variation will contribute to the model determination error. We estimate that the maximum possible difference in the latitude of the dip equator coming from the models and/or assuming an incorrect altitude, of at most $16 \mathrm{~km}$, for the EEJ is $\pm 9.8 \mathrm{~km}\left(0.088^{\circ}\right.$ at $108 \mathrm{~km}$ latitude $)$. This is well within the required $0.1^{\circ}$ resolution.

In the following discussions the model dip equator is determined as the point where the $\mathrm{Z}$ component of the model using gauss coefficients 1-14 (including secular terms 114) is zero at $108 \mathrm{~km}$ altitude. Because the secular term is included, the model dip equator was calculated for each individual satellite pass. The time used for each pass was the time when the satellite passed over the geographic equator. It takes the satellite approximately 30 minutes to pass from $40^{\circ}$ to $150^{\circ}$ latitude. It was assumed that during this short period the secular variation was unchanging. For the longitude region near $300^{\circ}$, where the difference between geographic and geomagnetic equators is largest, the very small shift in the time between the two equator crossings does not affect the results.

\section{Choice of Data}

The CHAMP satellite flies in a near circular orbit so approximately every 93.5 minutes the satellite crosses the equator at longitudes about $-24^{\circ}$ apart. This configuration means that the satellite will cover the whole globe longitudinally every 24 hours but remain at the same local time (give or take a few minutes). The precession rate is such that for local times between 0900 and 1600 the satellite will continuously measure for 77 days then break for either 37 days (descending mode) or 71 days (ascending mode). Thus, for four years data the local times 0900-1600 are measurable for all seasons.

Figure 5 shows the scalar field, at satellite altitude, along 


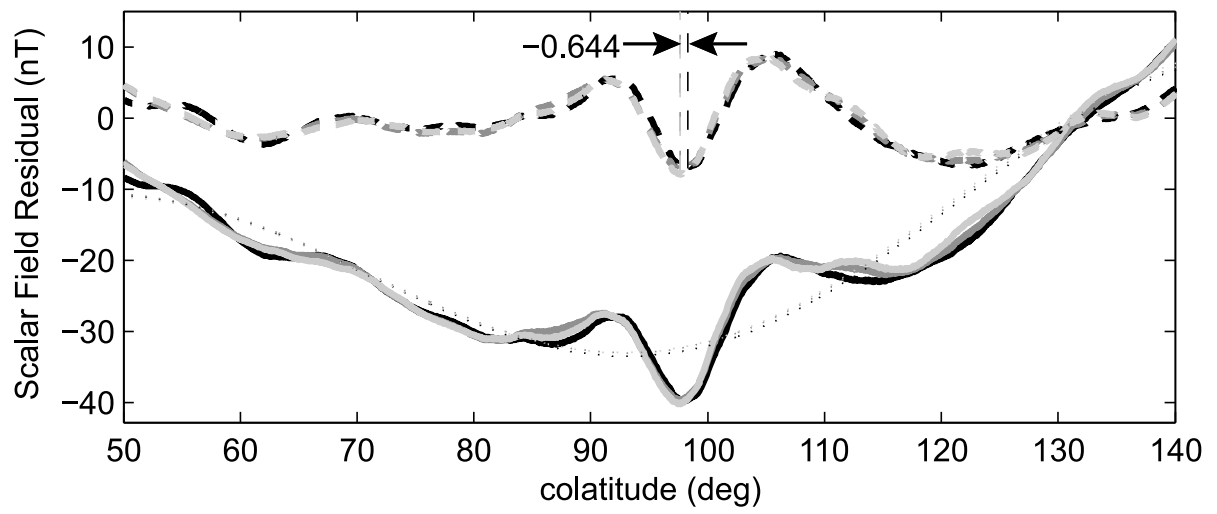

Fig. 5. The scalar field measured along a satellite pass after the core and lithospheric fields have been removed (solid lines). LW signature (dotted lines). The residual, after removal of the LW component (dashed line). Three models are represented; Ørsted_08i_03 (light grey), C02 (black) and MF3 (dark grey). The position of the minimum for each model (vertical dashed lines). MF3 and Ørsted_08i_03 overlap. Maximum difference between all three locations is shown.

a satellite track after the main and lithospheric fields have been removed using a field model (solid lines). Three models were used; Ørsted_08i_03 (light grey), C02 (black) and MF3 (dark grey). The long wavelength daytime magnetic field variation at mid and equatorial latitudes is mainly composed of effects from magnetospheric currents and the smaller, long wavelength part of the daily Sq variation. A method of subtracting the long wavelength component (LW) is described in Martinec and McCreadie (2004). This approximates the local LW part by a set of orthogonal Legendre polynomials (only polynomial degrees 0 through 2 are used here) for that part of the track that does not include the auroral regions. It was not deemed wise to separate the EEJ signature from the filter region as described by Maus et al. (2002) because there is debate surrounding the role of the EEJ in the Sq current system (Stening, 1995) and not enough is known about the return currents to determine the exact location of their cut off points. The computed LW signature is shown for each model in Fig. 5 (dotted lines). The differences between the LW components for each model are not large. The track, after removal of the LW component, is shown by the dashed line.

The EEJ signature from CHAMP scalar measurements is defined in McCreadie (2004) as, "one minimum lies within 2 degrees of the quasi-dip equator and one maximum occurs directly either side. These maximums must lie between $\pm 10^{\circ}$ of the quasi-dip equator. The resulting amplitude must be the maximum amplitude in the pass of this configuration." In this pass the EEJ signature is clearly visible between 85 and 110 geocentric colatitudes.

The algorithm used for finding the EEJ first determines the rough position of all maxima and minima within $\pm 30^{\circ}$ dip latitude (at satellite altitude). The mean for $2^{\circ}$ latitude bins is calculated and the gradient between each mean value is determined and when the sign of the gradient changes between consecutive means a maximum or minimum is noted. Exact geocentric locations of each maximum or minimum is then found by finding the lowest (highest) value of each minimum (maximum) within $\pm 3^{\circ}$ of rough minimum (maximum) location. The classification criteria described in McCreadie (2004) are then used to determine the type of signal encountered by the satellite for this pass. Only passes deemed EEJ type passes are used in this present study.

Figure 5 shows that the range of the position of the observed EEJ signature between the three models for this track is $0.644^{\circ}$. However, remember that the corresponding scatter in determining the dip equator is only $0.088^{\circ}$, so this cannot be the cause. The side lobes between $80^{\circ}$ and $90^{\circ}$ colatitude and $105^{\circ}$ and $120^{\circ}$ also show disparity between the models suggesting a lithospheric under/over misrepresentation.

\section{The Models and the EEJ Position}

Figure 6 is a plot of our estimate of the position of the EEJ for each satellite pass where an EEJ signature was found in the CHAMP Overhauser magnetometer observations from August 2000 until December 26, 2004. The calculation was made for each of the four models shown in Table 1 . The black line on each graph shows the mean position calculated over two degrees of longitude. The variance of the points about the mean is shown in the bottom graph of each plate. The variance is greatest near $300^{\circ}$ longitude for all models. This is the region of the South Atlantic anomaly where the core field is low (see Fig. 1) and the secular variation is most rapid (see Fig. 4). This suggests that the core field modelling of this region may need more work.

A problem with any model is deciding what is real and what is not. To illustrate this, cast your eye to the arrows on each graph. The arrows are in the same position relative to each axis [10.0 longitude, 1.0 latitude]. The same initial data set has been used to obtain each graph: only the subtracted model is different. With the two models of higher orders (Ørsted_08i_03 and MF3), therefore shorter wavelengths, an increase in the number of points which lie away from the dip equator and a shift in the longitudinal position of the points which lie away from the dip equator compared to the other two models (Ørsted_06a_01 and C02) is apparent. This area over Africa contains a large known lithospheric anomaly (see Fig. 1(B)). Clearly, this region requires closer attention. At present there is no way to tell which model is representing the African equatorial lithospheric anomaly best at the dip equator.

The red dots represent a longitude zone where the latitudinal position of the mean differs greatly from model 
(A) $\mathrm{C02}$
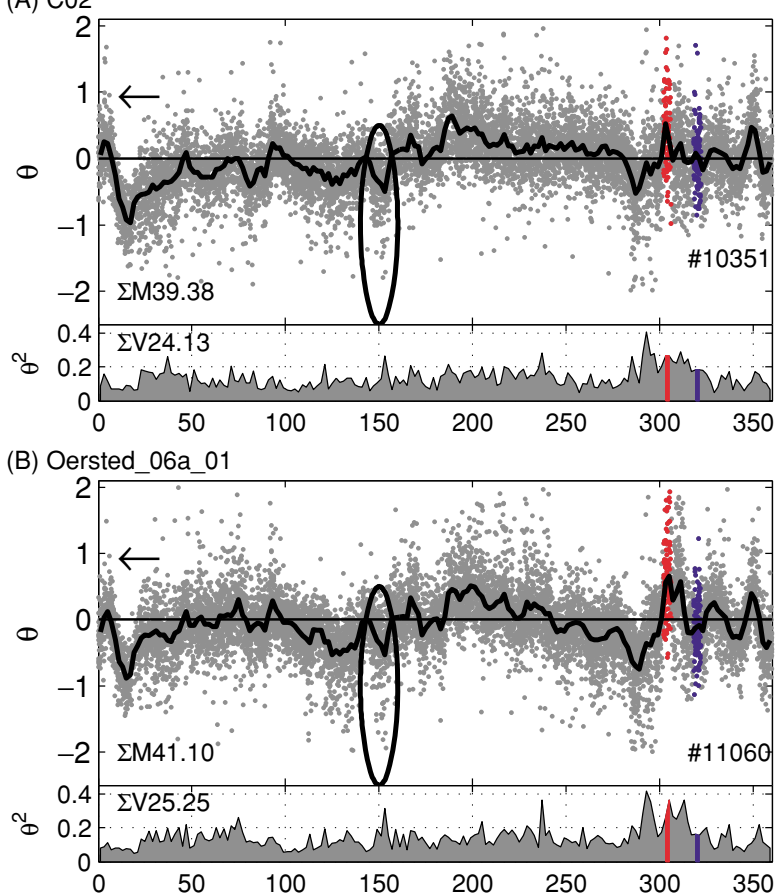

(C) MF3

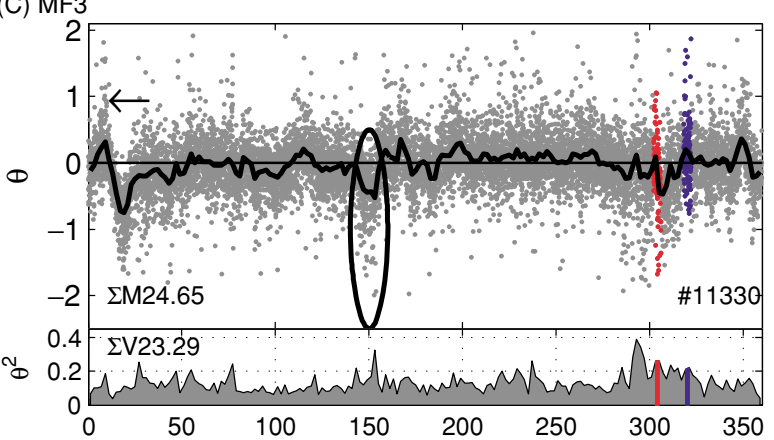

(D) Oersted_08i_03

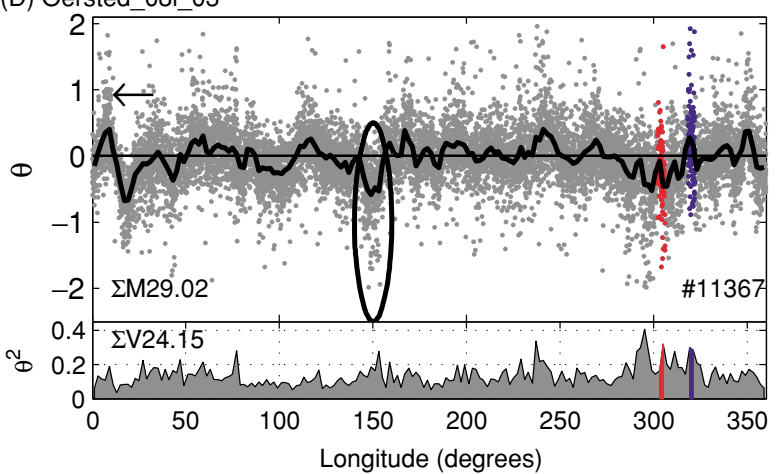

Fig. 6. Latitude deviation of the EEJ, from the dip equator (grey, blue and red dots) calculated for each model at $108 \mathrm{~km}$ altitude. The abscissae are longitude in degrees. The mean calculated for 2 degree longitude bins (thick solid line). The lower graph shows the variances of points about the means. The arrow and oval are located at the same position on each graph. The blue and red dots highlight areas of discrepancy between the different models. The total number of points (\#), sum of the absolute value of mean $(\Sigma M)$ and the sum of the variances $(\Sigma V)$ are shown for each graph.

to model. The two lower order models (CO2 and Ørsted_06a_01) place the mean position north of the dip equator whilst the Ørsted_08i_03 model positions the equator just south of the dip equator and the MF3 model posi- tions the equator both north and south for this zone. Which model shows the true position? A further illustration is shown with the longitude zone colored blue. Here the opposite is seen where for the higher order models the mean position is north of the dip equator, the $\mathrm{CO} 2$ model is just north and the Ørsted_06a_01 is south of the dip equator. We saw that the difference between the model dip equators is at most $0.025^{\circ}$. Therefore, the cause of this apparent shift in position must be the differences in the modeled lithospheric fields. It is true that at these longitudes differences in the lithospheric fields which have a similar structure to the EEJ are apparent (see Fig. 2(C)).

Major disparities covering a small area of longitude are highlighted with black ovals. The variance for each area is similar suggesting that this area, even though the variance is high, is modelled similarly.

Also included on each graph is the number of passes deemed EEJ out of a possible 14081 passes (number after the hash). One would think it would be the same for each model. However, if a lithospheric anomaly is underestimated or overestimated and is of a similar structure and smaller or similar wavelength and amplitude as the EEJ signature at satellite altitude then an EEJ signal will be found using the method used here even if there was none. Conversely, if a lithospheric field anomaly is not mapped (African zone) the data are again affected.

How are the data affected? When locating the position of the EEJ we are finding the position of the minimum of an inverted bell shape, with respect to a horizontally aligned axis in the North-South plane (X-axis). Moving the $\mathrm{X}$-axis bodily up or down (say by adding a homogenous lithospheric anomaly) will have no effect on the position of the EEJ. However, if the X-axis is tilted (say by an anomaly that is asymmetric) the position of the EEJ will be affected. This suggests that the absolute value of the perturbing field is not relevant but the gradient of the perturbation near the EEJ is (Frank Lowes, communication during the referee process).

To estimate the effect let's approximate the observed EEJ field as

$$
E=-C \cos m \theta
$$

Where $\theta$ is latitude (or distance from a nominal $Z=0$ latitude) in radians, and the amplitude of the EEJ is $C=2$ nT, and $m=18$ ( $10^{\circ}$ width), and $E$ is the scalar field. Adding a local perturbation of

$$
P=A-B \theta,
$$

where $B$ is the North-South gradient in nT/radians. So what is observed is

$$
F=E+P=-C \cos m \theta+A-B \theta .
$$

The position of the observed EEJ will be located at the point where $d F / d \theta=0$ (the minimum scalar field). This gives,

$$
d F / d \theta=C m \sin m \theta-B=0 .
$$

But the displacement $\theta$ is very small, so we can approximate $\sin m \theta$ by $m \theta$ giving,

$$
B=C m 2 \theta \text {. }
$$



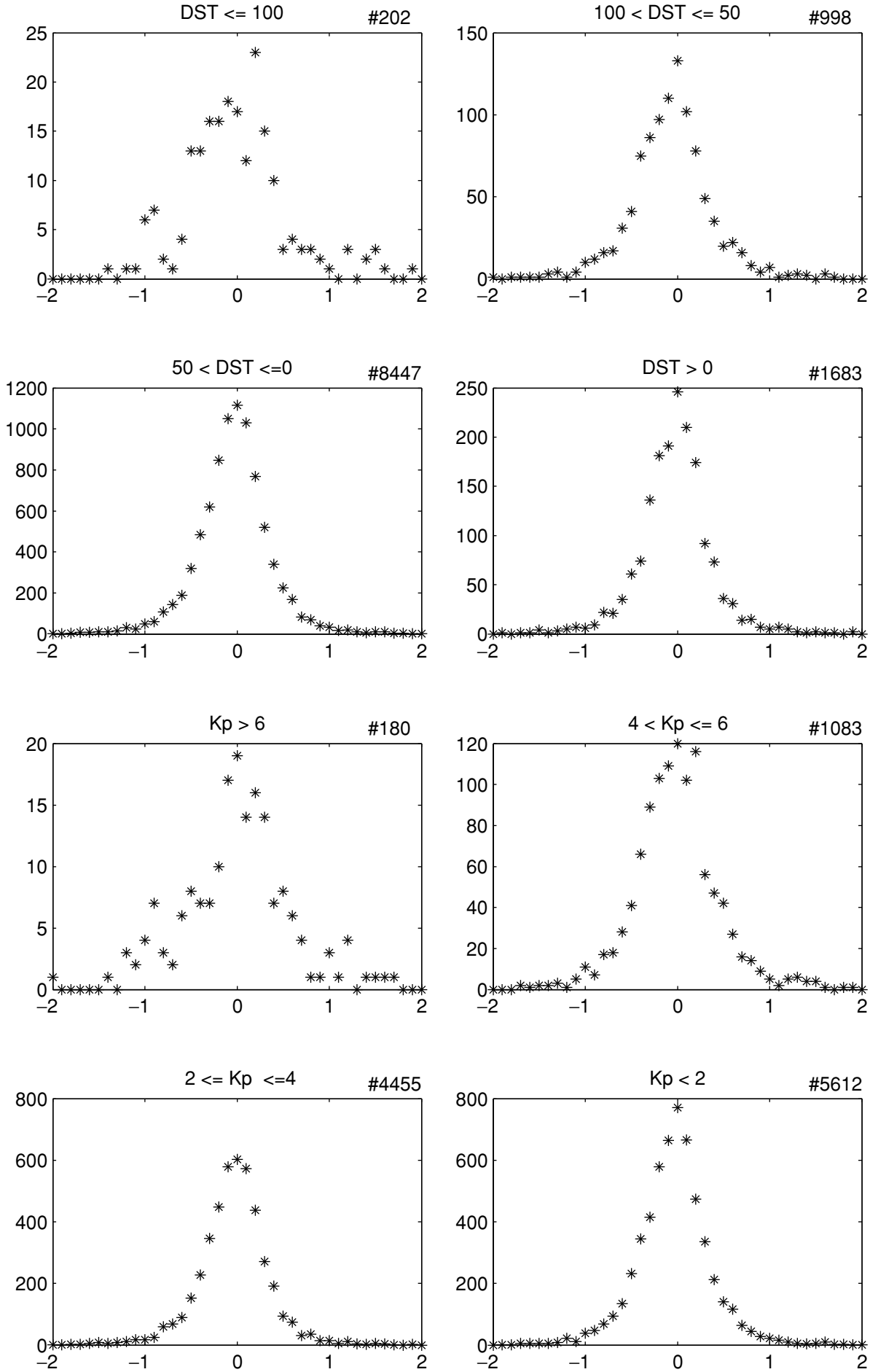

Fig. 7. Frequency versus position of the EEJ plots for various degrees of magnetic activity determined from $K p$ and $D s t$ indices. The total number of points (\#) is shown for each plot.

Figure 6 shows displacements of up to 0.5 degrees; this gives $B=0.1 \mathrm{nT} /$ degree. Figure 2(B) shows crustal field differences of amplitude up to about $2 \mathrm{nT}$, having wavelengths of about 20 degrees. A sine wave of amplitude $S$, wavelength $\lambda^{\circ}$, has a gradient ranging from zero to $2 \pi S / \lambda$, so the difference field of Fig. 2(B) will have gradients up to about $0.6 \mathrm{nT} /$ degree in some places; hence the shift in the mean position of the EEJ between the models in Fig. 6.

Using the definition, "the position of the EEJ lies on the dip equator", as the criterion for choosing the best model is then it is clear that the MF3 and Ørsted_08i_03 models do best at most longitudes. For a quantitative estimate for the whole globe the sum of all the mean positions and the sum of the variances will give a measure of the relative "goodness" of each model. On each graph in Fig. 6 the sum of the absolute mean position is the number after the $\Sigma M$ and the sum of all variances is given after the $\Sigma V$. These show that higher order models fit the request because their sums are the lowest; the MF3 outperforming the others. Thus, the MF3 was chosen for the following analysis. 

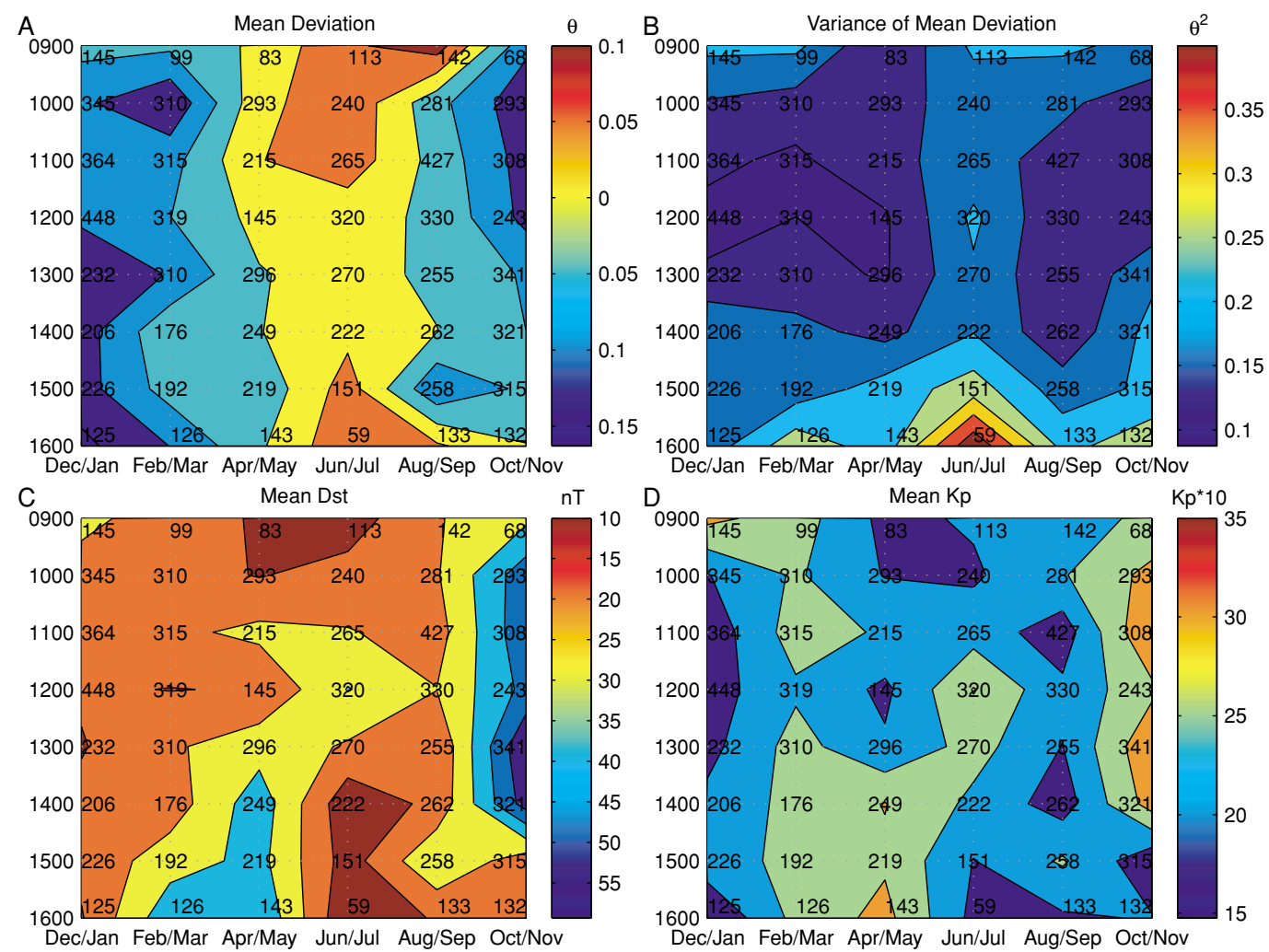

Fig. 8. The diagrams show contour plots for various quantities, based on data which has been binned over 1 hour of the day in local time (ordinate) and 2 months (abscissa) in the year. The numbers at the bin points are the number of data contributing to that bin. (A) The mean deviation position of the EEJ from the dip equator, (B) Variance of the mean in (A), (C) Mean $D s t$ and (D) Mean $K p$ NB: $K p$ value is multiplied by 10.

\section{Outliers: Caused by Magnetic Activity?}

For the 11330 EEJ signatures determined from the Ørsted_08i_MF3 model, $83.4 \%$ lie within $0.5^{\circ}$ of the dip equator, $13.7 \%$ lie between 0.5 and 1.0 , and $2.9 \%$ lie outside the range of $1.0^{\circ}$. These percentages are averages over all states of the magnetosphere and ionosphere. Figure 7 shows frequency of occurrence of a particular deviation of the EEJ from the dip equator for various degrees of magnetic activity determined from $K p$ and $D s t$ indices. The minor fluctuations in the Gaussian distribution for the high activity bins may just be due to lack of data. During high magnetic activity the location of the EEJ is just as likely to be $0^{\circ}$. The conclusion drawn is magnetic activity is not the reason for the outliers (tracks with EEJ location greater than 1 degree).

\section{Time of day and season}

There are known seasonal and daily variations in the amplitude of the EEJ (see for example the reviews, Onwumechilli (1997), Forbes (1981) and the series Fambitakoye et al., 1976/(1-4)). Is the position of the EEJ also likely to deviate from the dip equator at a specified time of day or a specified season? Figure 8(A) shows the mean position of the EEJ signature for the specified local time (centred on the hour) and time of year split into twomonth segments. There is a clear annual variation in the position of the EEJ: its position is more southern in December/January and zero or slightly more northern in June/July months. Fewer deviations from zero occur at local times $1200-1400$ for the June/July months. This is also shown by
Lühr et al., 2004. Their figure 4 shows the distribution of current density (calculated from CHAMP scalar measurements for passes with $K p<2$ ) with northern hemisphere seasons (winter being December/January). The variation of current density is greatest in December/January. Their figure 5, bottom, shows the distribution of peak current density with distance from the dip equator. When the current density is maximised the position of the peak current density is clearly more southern.

What is more interesting is the variance about the mean shown in Fig. 8(B). The variance is greater in the June/July months than in December/January months. As expected, because the EEJ is smaller in amplitude in the morning and afternoon hours, thus more susceptible to outside influences (see the reviews cited above) the determination of the position of the EEJ should be more variable than during midday hours. This susceptibility to outside influences is also apparent in the severe reduction in the number of passes which contain an EEJ signal in the morning and evening hours.

Figure 8(D) shows the distribution with $K p$. As noted before there does not appear to be any correlation with $K p$. Figure $8(C)$ shows the Dst distribution. This shows a weak correlation between mean $D s t$ and the mean position. When the mean Dst is more positive (few or no large storms) there is a greater tendency for the EEJ to be located in the north. What could this mean? It is suggested that the ring current has an annual variation (Malin and Isikara, 1976; Butcher and Schlapp, 1992; Stening and Winch, 1987; McCreadie, 1998). Perhaps removal of the ring current field (the major component of the LW filter) 
here has not been performed correctly. McCreadie (1998) and Butcher and Schlapp (1992) noted that the annual variation was composed of two terms; one highly correlated with ring current motion and another term that is very highly correlated with the amplitude and phase of the annual variation of the $\mathrm{H}$ component of the equatorial station, Huancayo. The source of this component has yet to be determined. However, the cause of this term may be the reason for the annual variation in the position of the EEJ.

\section{Conclusions}

Differences between different main field models show for certain regions a long wavelength signature with amplitude close to $5 \mathrm{nT}$ in the core field component. This suggests that for certain regions a direct comparison between scalar geomagnetic measurements that use different models to remove the main field may not be reasonable. We also show that some lithospheric anomalies on and near the dip equator have a latitudinal form similar to that of the EEJ.

A comparison of the dip equators from two core field models suggests that the intrinsic error in the determination of the dip equator latitude from a model, including secular variation terms, is about $0.027^{\circ}( \pm 3 \mathrm{~km})$. Using one of the models to determine the possible latitudinal error involved in determination of the variation with altitude of the EEJ we found $0.06^{\circ}( \pm 6.8 \mathrm{~km})$ for a $16 \mathrm{~km}$ altitude underestimation. Thus, the maximum possible error in the location of the EEJ imposed by using the models and/or assuming an incorrect altitude, of at most $16 \mathrm{~km}$, for the EEJ is $\pm 9.8 \mathrm{~km}$ $\left(0.088^{\circ}\right.$ at $108 \mathrm{~km}$ latitude). This is well within the required $0.1^{\circ}$ resolution for comparisons with ground measurements.

Using geomagnetic scalar measurements from the CHAMP satellite, the location of the EEJ signature was determined after subtracting four main field models. We find that the location can be statistically determined to within $\pm 0.5^{\circ}$ of the dip equator irrespective of longitude, time of the measurement, and degree of magnetic activity, for any model. However, for certain longitudes the deviation of the EEJ from the dip equator is as much as $0.8^{\circ}$. These deviations happen in areas with large lithospheric anomalies on or near the dip equator suggesting that the longitudinal variations in the position of the EEJ are sometimes caused by the actual model and are not always a physical phenomenon.

By choosing one model, and assuming it is the best representation of the main field, we have also shown that determination of the EEJ is reduced in the morning and evening hours and that a morning and evening shift in the location of the EEJ found using ground data is also seen in the satellite measurements. There exists a clear annual variation in the position of the EEJ regardless of longitude; it being south of the dip equator in December which is in agreement with the findings of all previous studies without exception.

Acknowledgments. We wish to thank the CHAMP and Ørsted teams for the valuable geomagnetic data and models. This work was supported by Kyoto University Active Geosphere Investigations for the 21st Century Centers of Excellence Program Japan, WDC for Geomagnetism and Space Magnetism Kyoto, and also GeoForschungsZentrum-Potsdam postdoctoral award. We also wish to thank Frank Lowes for the effort he put into reviewing this work. This would never have been published without his astute comments and suggestions.

\section{References}

Butcher, E. C. and D. M. Schlapp, The annual variation of the night-time values of the geomagnetic field, Geophys. J. Int., 111, 151-158, 1992.

Chambodut, A., J. Schwarte, G. B. Langlais, H. Lühr, and M. Mandea, The selection of data in field modeling, Oist-4 Proceedings: 4th Ørsted International Science Team Conference, Copenhagen, September 23-27, 2002, edited by P. Stauning, H. Lühr, P. Ultre-Geurard, J. LaBrecque, M. Purucker, F. Primdahl, J. Joergenson, F. Christiansen, P. Hoeg, and K. Lauritsen, Narayana Press. pp. 31-34, 2003.

Chapman, S. and J. Bartels, Geomagnetism Vols. I and II, Oxford University Press, 1940.

Deka, R. C., L. A. D’Cruz, V. J. Jacob, A. Iype, and P. Elango, Location of the dip equator over Peninsular India, J. Ind. Geophys. Union., 9(1), 41-46, 2005.

Fambitakoye, O. and P. N. Mayaud, Equatorial Electrojet and Regular Daily Variation SR-I. A Determination of the Equatorial Electrojet Parameters, J. Atmos. Terr. Phys., 38, 1-17, 1976/1.

Fambitakoye, O. and P. N. Mayaud, Equatorial Electrojet and Regular Daily Variation SR-II. The Centre of the Equatorial Electrojet, J. Atmos. Terr. Phys., 38, 19-26, 1976/2.

Fambitakoye, O. and P. N. Mayaud, Equatorial Electrojet and Regular Daily Variation SR-IV. Special Features in Particular Days, J. Atmos. Terr. Phys., 38, 123-134, 1976/3.

Fambitakoye, O., P. N. Mayaud, and A. D. Richmond, Equatorial Electrojet and Regular Daily Variation SR-III. Comparison of Observations with a Physical Model, J. Atmos. Terr. Phys., 38(2) 113-121, 1976.

Forbes, J. M., The equatorial electrojet, Rev. Geophys. Space Phys., 19, 469-504, 1981.

Holme, R., N. Olsen, M. Rother, and H. Lühr, C02-A CHAMP Magnetic Field Model, in First CHAMP Mission Results for Gravity, Magnetic and Atmospheric Studies, edited by C. Reigber, H. Lühr, and P. Schwintzer, Springer, Berlin; Praxis Publishing. pp. 220(6), 2003.

Jadhav, G., M. Rajaram, and R. Rajaram, Main Field Control of the Equatorial Electrojet: a Preliminary Study from the Oersted Data, J. Geodynamics, 33, 157-171, 2002.

Langel, R. A. and R. H. Estes, A geomagnetic field spectrum, Geophys. Res. Lett., 9, 250-253, 1982.

Lowes, F. J. and J. E. Martin, Optimum use of satellite intensity and vector data in modelling the main geomagnetic field, PEPI, 48, 3-4(10): 183192, 1987.

Lühr H., S. Maus, and M. Rother, Noon-time equatorial electrojet: Its spatial features as determined by the CHAMP satellite, J. Geophys. Res., 109, A01306, 2004, doi:10.1029/2002JA009656.

Malin, S. R. and A. M. Isikara, Annual variation of the geomagnetic field, Geophys. J. R. Astr. Soc., 47, 445-457, 1976.

Martinec, Z. and H. McCreadie, Magnetic induction modelling based on satellite magnetic vector data, Geophys. J. Int., 157, 1045-1060, 2004 doi: 10.1111/j.1365-246X.2004.02252.x.

Maus, S., M. Rother, R. Holme, H. Lühr, N. Olsen, and V. Haak, First scalar magnetic anomaly map from CHAMP satellite data indicates weak lithospheric field, Geophys. Res. Lett., 29, 2002, doi:10.1029/2001GL013685.

McCreadie H., Annual and Semi-annual harmonics of the midnight geomagnetic field, Ph.D thesis, Bochardt library, LaTrobe University, Bundoora Australia, 1998.

McCreadie H., Classes of the equatorial electrojet, Earth Observation with CHAMP Results from Three Years in Orbit, Springer Geosciences Series, edited by C. Reigbar, H. Lühr, P. Schwintzer, and J Wicket, pp. 401-406, 2004.

Olsen, N., A model of the geomagnetic field and its secular variation for Epoch 2002 estimated from Ørsted data, Geophys. J. Int., 149, 453-461, 2002.

Onwumechili, C. A., The Equatorial Electrojet, OPA Amsterdam, 1997.

Stening, R. J., What drives the equatorial electrojet?, J. Atmos. Terr. Phys., 57(10), 1117-1128, 1995.

Stening, R. J. and D. E. Winch, Night-time geomagnetic variations at low latitudes, Planet. Space Sci., 35, 1523-1539, 1987.

H. McCreadie (e-mail: heather.mcCreadie@dsto.defence.gov.au) and T. Iyemori 